\title{
Transfer-Messenger RNA
}

National Cancer Institute

\section{Source}

National Cancer Institute. Transfer-Messenger RNA. NCI Thesaurus. Code C95954.

An RNA encoded by the bacterial ssrA gene. It is involved in the recycling of stalled ribosomes and the targeting of both defective mRNA molecules and incomplete nascent proteins for degradation. 